\title{
IDENTIFICAÇÃO E COMPREENSÃO DE SINTOMAS DEPRESSIVOS NA INFÂNCIA EM CONTEXTQ ESCOLAR: DESAFIOS CONTEMPORANEOS DO EDUCADOR
}

\author{
IDENTIFICATION AND COMPREHENSION OF DEPRESSION SYMPTONS DURING \\ THE CHILDHOOD IN A SCHOOL CONTEXT: CONTEMPORARY CHALLENGES FOR \\ THE EDUCATOR
}

\author{
IDENTIFICACIÓN Y COMPRENSIÓN DE LOS SÍNTOMAS DEPRESIVOS EN LA \\ INFANCIA EN EL CONTEXTO ESCOLAR: RETOS CONTEMPORÁNEOS DE LO \\ EDUCADOR
}

\author{
Marlene Nogueira Pinheiro* \\ marlenero17@hotmail.com \\ Wyara Dimas Campos Sousa** \\ wyaradimas@gmail.com \\ José Ricardo Teles Feitosa*** \\ feitosaric@hotmail.com \\ Eraldo Carlos Batista**** \\ eraldo.cb@hotmail.com
}

REVISTA PEDAGÓGICA

Revista do Programa de Pós-graduação em Educação da Unochapecó | ISSN 1984-1566 Universidade Comunitária da Região de Chapecó | Chapecó-SC, Brasil Como referenciar este artigo: PINHEIRO, M. N.; SOUZA, W. D. C.; FEITOSA, J. R. T.; BATISTA, E. C. Identificação e compreensão de sintomas depressivos na infância em contexto escolar: desafios contemporâneos do educador. Revista Pedagógica, Chapecó, v. 19, n. 40, p. 155-171, jan./abr. 2017. DOI: http://dx.doi.org/10.22196/rp.v19i40.3748

RESUMO: Durante muito tempo,acreditou-se que a criança não tinha depressão significativa,pensamento que se revelou bastante equivocado, porque em estudos científicos foram encontradas evidências de que a depressão ocorre pelo menos ocasionalmente entre crianças. Com base nesse ponto de vista, o presente artigo socializa um estudo cujo objetivo foi discutir sobre a importância do educador na compreensão e na identificação dos sintomas depressivos em alunos. A busca através da literatura mostrou que a depressão traz sérias consequências à vida da criança, principalmente em contexto escolar, podendo interferir na aprendizagem, pois, durante o período depressivo infantil, a perda de interesse pelas atividades que antes eram divertidas dá lugar a manifestações de mau humor constante diante dos estudos, dos jogos, das brincadeiras e dos esportes, causando significativos danos psicossociais. O estudo evidenciou estratégias que podem contribuir para a atuação do educador em sala de aula com crianças que manifestem algum tipo de comportamento específico, classificado como transtorno depressivo, e comprovou que este profissional é sujeito importante na identificação de sintomas da depressão infantil.
ABSTRACT: For a long time, it was believed that children did not have significant depression, a thought recently proved wrong, since it was found evidences in scientific studies that depression occurs at least occasionally among children. Based on this point of view, this research had as objective to discuss the importance of the educator on the comprehension and identification of symptoms of depression on students. The search through the literature has showed that depression has serious consequences to the child's life, especially in school context, which could interfere with the learning, since during the depressive period the loss of interest for activities that were once fun, gives place to demonstrations of constant bad mood in face of studies, games and sports, causing significant psychosocial damage. Our study evidenced strategies that can contribute in the teacher performance in classes with children who express some kind of specific behavior, classified as depressive disorder, and shown that teachers are important for the identification of symptoms of childhood depression.

Keywords: Depression During Childhood. School Context. Educator.

Palavras-chave: Depressão infantil. Contexto Escolar. Educador. 
* Acadêmica de Psicologia da Faculdade de Rolim de Moura - FAROL

*** Acadêmica de Psicologia da Faculdade de Rolim de Moura - FAROL

**** Doutor em Geografia Pela Universidade Federal do Paraná - UFPR

***** Doutorando em Psicologia pela Pontifícia Universidade Católica - PUCRS, Mestre em Psicologia pela Fundação Universidade Federal de Rondônia - UNIR, Especialista em Saúde Mental pela Universidade Católica Dom Bosco - UCDB, Docente da Faculdade São Paulo - FSP
RESUMEN: Durante mucho tiempo se creyó que la niño no tenía depresión significativa, pensamiento que resultó ser un gran error, ya que en los estudios la evidencia científica se encontró que la depresión se produce por lo menos de vez en cuando desde los niños. Desde este punto de vista, este artículo socializa un estudio cuyo objetivo fue discutir acerca de la importancia del maestro en la comprensión y identificación de síntomas depresivos en alumnos. La búsqueda a través de la literatura mostró que la depresión trae graves consecuencias para la vida del niño, especialmente en las escuelas y pueden interferir con el aprendizaje, debido a que durante el periodo depresivo en la infancia, la pérdida de interés en actividades, los juegos y deportes, causando daños psicosocial significativo. El estudio resalta estrategias que pueden contribuir a el rendimiento del educador en el aula con los niños que expresan algún tipo de comportamiento específico, clasificado como un trastorno depresivo, y demostró este profesional es sujeto importante en la identificación de síntomas de la depresión infantil.

Palabras clave: La depresión infantil. Contexto escolar. Educador.

\section{INTRODUÇÃO}

Durante um longo período, a depressão foi refletida como uma característica de classificação patológica exclusivamente do adulto. No entanto, estudos mostram que a manifestação de sintomas depressivos afeta também crianças e adolescentes, trazendo prejuízos aos relacionamentos familiar, social e escolar. Na vida acadêmica,a depressão pode estar relacionada à redução do nível de aprendizagem e à evasão escolar (NOGUEIRA; SANTOS; FONSECA, 2016; BALLONE, 2015; HUTTEL et al., 2011; FERNANDES; MILANI, 2010).

Os transtornos depressivos que afetam o comportamento do indivíduo na infância se constituem tanto pelo aumento da frequência quanto pelo grau de sofrimento e de disfunções instantâneas, sendo associados a um problema de saúde pública, pois trazem sérias consequências psicológicas, sociais, familiares e econômicas para a sociedade. De acordo com Vinocur e Pereira (2011), na maioria dos países, estudos têm demonstrado que a alteração do desenvolvimento está associada ao crescimento de transtornos mentais e comportamentais na infância e na adolescência, apresentando taxa de $10 \%$ a $20 \%$, podendo ocorrer um crescimento significativo nos anos seguintes em crianças vítimas dos respectivos transtornos.

No Brasil, os dados têm sido considerados preocupantes em comparação com as taxas de crianças de outros países. Atualmente, calcula-se que uma entre 4 a 5 crianças e adolescentes no mundo apresentam algum transtorno mental e, na maioria das vezes, os sinais e sintomas são desconsiderados pela família e professores.Dentre os fatores associados às alterações do comportamento na infância e que podem se tornar contribuintes para o surgimento de transtornos depressivos,elencam-se as condutas antissociais, a delinquência e o uso de drogas (THIENGO; CAVALCANTE; LOVISI, 2014;VINOCUR; PEREIRA, 2011).

Diante de tal constatação, compreende-se que o diagnóstico precoce deve ser considerado como instrumento fundamental para a prevenção da depressão infantil. 
Seguindo esse princípio,os órgãos governamentais que regem as diretrizes de direito à saúde têm demonstrado iniciativas para promoção e prevenção social do indivíduo.A escola como ponto referencial nesse processo de saúde integral da criança passa a ser um campo estratégico e privilegiado por compor uma gama de possibilidades que contemple a relação de professor e aluno, visto que esta possibilita a identificação de problemas emocionais e comportamentais.

Partindo do princípio de que prevenção e a intervenção da saúde psíquica emocional da criança passam também pelas estratégias pensadas e desenvolvidas pela equipe escolar, o objetivo deste estudo foi discutir as ações que viabilizam a prática do educador no processo de identificação dos sintomas depressivos nas crianças, evidenciando como este profissional pode lidar com aquelas que já apresentam algum tipo de transtorno mental, sobretudo os sintomas depressivos.

\section{SÍNDROMES DEPRESSIVAS}

Registrada desde tempos remotos e presente nas variadas populações do mundo, a depressão é um transtorno do humor grave que pode ocorrer em todas as faixas etárias, transformando-se em uma patologia cada vez mais frequente na atualidade. Quanto a suas características, a depressão pode se manifestar, em casos mais graves, com queixa psíquica de humor deprimido, fadiga, sensação de perda de energia, dificuldade de concentração, perda de memória e até suicídio.Ainda pode se apresentar por meio de queixas somáticas, por exemplo: aumento ou diminuição de sono, apetite e peso. Podem ocorrer, também, alterações no comportamento, tais como: retraimento social, crises de choro, abandono de atividades habituais, retardo ou agitação psicomotora (DEL PORTO, 2000).

Segundo o DSM-V (2014), a síndrome depressiva tem como características comuns a presença de humor triste, vazio ou irritável, acompanhado de alterações somáticas e cognitivas que afetam, significativamente, a capacidade do funcionamento do indivíduo, para designar um estado de desânimo ou perda de interesse. Do ponto de vista psicopatológico, essas síndromes têm como elementos mais salientes o humor triste e o desânimo e elas se caracterizam por sintomas afetivos, instintivos e neurovegetativos, ideativos e cognitivos, relativos à autovaloração, à vontade e à psicomotricidade. É um transtorno de humor que se caracteriza por tristeza e anedonia associados a transtornos de sono como a insônia ou a hipersônia, de alimentação e outras morbidades (DALGALARRONDO, 2008).

Já a Classificação Internacional de Doença (CID-10) descreve que em cada episódio típico de cada um dos três tipos de depressão: leve, moderado ou grave, o paciente apresenta uma série de sintomas que se manifestam em todos os três tipos de depressão: 
[...] rebaixamento do humor, redução da energia e diminuição da atividade. Existe alteração da capacidade de experimentar o prazer, perda de interesse, diminuição da capacidade de concentração, associadas em geral à fadiga acentuada, mesmo após um esforço mínimo. Observam-se em geral problemas de sono e diminuição do apetite. Existe quase sempre uma diminuição da autoestima e da autoconfiança e frequentemente ideias de culpabilidade e/ou indignidade, mesmo de formas leves. (CID-10, 2012, p. 30).

O humor, sendo o estado de ânimo/emocional de uma pessoa, pode variar sua intensidade de acordo com o grau de disposição e bem-estar patológico, e condições físicas e mentais de cada indivíduo. As emoções podem surgir, em uma variedade de ocasiões, como resposta a alguma situação, seja ela positiva - "feliz" - ou negativa - "triste". Essas expressões são formas que o cérebro busca para responder a determinados sentimentos (DSM-V, 2014).

Kutcher et al. (2014) afirmam que, em geral, a depressão é semelhante para todos, mas a forma de expressá-la pode ser muito diferente dependendo da idade. Ou seja, crianças menores podem apresentar muito mais sinais verbais, como expressão facial triste, desinteresses por coisas que gostavam etc., ao passo que adolescentes apresentam mais sinais de sono e de apetite.

Ainda de acordo com os autores supracitados, a depressão é multifatorial, e a genética tem sido o mais importante desses fatores. Porém, outros fatores como contexto familiar conturbado, vivência de situações estressantes e padrões de raciocínio, por exemplo, podem ocasionar a depressão na criança (KUTCHER et al., 2014). A isso se acrescenta a experiência de perdas significativas, abuso emocional, físico e/ou sexual que podem levar a criança a se isolar, evitando contato social por apresentar autoestima reduzida e não conseguir ter prazer em atividades que normalmente lhes causariam satisfação. Lima (2004) nos remete à ideia de que crianças que sofrem agressão sexual geralmente se sentem culpadas, envergonhadas, demonstram ansiedade e têm uma propensão a se tornarem agressivas; esses sintomas ocorrem em concomitância com sintomas depressivos.

Como mencionado anteriormente, o histórico familiar depressivo pode ser indicador de probabilidade maior de a criança apresentar transtorno depressivo ou humor triste do que ao contrário. Nesse diapasão, Lafer e Amaral (2000) afirmam que crianças com pais deprimidos possuem um risco três vezes maior de desenvolverem essa patologia do que as que não possuem pais com depressão. Desse modo, a depressão nos filhos pode ser transmitida pelos pais depressivos, tanto através da imitação que esses filhos fazem dos comportamentos depressivos dos pais, gerando assim, a depressão denominada exógena, como 
pela possibilidade de herança genética, que caracteriza a depressão endógena (FIHRER; MCMAHON; TAYLORT, 2009).

Portanto, os fatores causais da depressão não são em si excludentes, mas sim complementares, envolvendo o sujeito em sua totalidade.

\begin{abstract}
A depressão, sem dúvida, integra fatores sócio-familiares [sic], psicológicos e biológicos, onde as diferentes teorias não se excluem, mas se completam, contribuindo não somente para uma maior compreensão da natureza multicausal deste transtorno mas também para a concepção do sujeito em sua totalidade biopsicossocial (CRUVINEL; BORUCHOVITCH; SANTOS, 2008, p. 79).
\end{abstract}

Nesse sentido, independentemente das causas que levam à manifestação dos sintomas depressivos, de alguma forma elas irão acarretar prejuízos irreversíveis na vidada criança em idade escolar. O declínio no desempenho escolar decorrente das consequências do transtorno frequentemente se torna um dos principais conflitos, pois o infante passa a ter dificuldade de concentração ou falta de interesse. Além disso, as fobias, a ansiedade de separação e as dores somáticas podem levar à recusa em ir à escola, bem como ao isolamento e à dificuldade em fazer amigos (CARMO; SILVA, 2009).

Em linha com esse parecer, nos últimos tempos, muitos estudos têm estabelecido a relação entre transtornos depressivos e rendimento escolar inferior entre crianças e adolescentes. Sendo assim, buscar-se-á, a seguir, fazer um breve levantamento dentro do parâmetro nacional de pesquisas realizadas com estudantes e das implicações da depressão na vida escolar.

\title{
3. INCIDÊNCIA DE DEPRESSÃO INFANTIL EM CONTEXTO ESCOLAR
}

No Brasil, apesar da escassez de estudos epidemiológicos, os resultados de algumas investigações têm revelado altos índices de presença de sintomas depressivos entre escolares adolescentes e crianças. Esses estudos têm contribuído com o levantamento de características relevantes para o diagnóstico de transtorno, sobretudo das diferenças de gênero.

Rocha et al. (2006),em um estudo com adolescentes de todas as idades,encontrou níveis altos de sintomas depressivos entre os avaliados, e a prevalência foi duas vezes maior no sexo feminino.Da mesma forma, o estudo amplo realizado por Golfeto et al. (2011), que teve por objetivo investigar a prevalência de sintomas depressivos em 5.974 alunos na faixa etária entre 6 e 18 anos de ambos os sexos de diferentes regiões,também constatou diferença estatisticamente significativa entre os gêneros, com maior 
incidência de sintomas depressivos no sexo feminino do que no masculino.

Em outro estudo - realizado por Fonseca, Ferreira e Fonseca (2005), no Estado de Minas Gerais, com 519 estudantes de sete a 13 anos de idade-, constatou-se que $13,7 \%$ dos escolares apresentaram sintomas de depressão. No referido estudo, as respostas mais encontradas foram: "Eu tenho certeza que coisas horríveis vão acontecer comigo", "Eu sempre me preocupo com dores", e "Nunca vou ser tão bom quanto os outros". Entretanto, nesse estudo não foi encontrada uma diferença significativa em relação ao gênero.

A presença de sintomas depressivos também altera a maneira como a criança lida com as emoções e suas representações. Em uma pesquisa realizada por Cruvinel e Boruchovitch (2011), que teve como objetivo avaliar o nível emocional de 54 crianças divididas em dois grupos (em um deles, havia a presença de sintomas depressivos e o outro não apresentava a sintomatologia), concluíram que os dois grupos utilizavam métodos semelhantes para lidar com as diferentes emoções; entretanto, os alunos com sintomas depressivos sentiam mais frequentemente tristeza e raiva. Nessa mesma direção, Ribeiro et al. (2007)buscaram investigar as representações sociais dos sintomas depressivos elaboradas por 553 crianças de ambos os sexos e os resultados evidenciaram que a depressão está relacionada principalmente a fatores psicossociais, que são expostos pelas crianças como falta de amigos, isolamento e medo de ser rejeitado.

Esses dados demonstram que a fase dos sintomas depressivos acarreta na criança a perda de interesse pelas atividades que antes eram divertidas e oferece lugar para manifestações de mau humor constante diante dos estudos, dos jogos, das brincadeiras e dos esportes, causando significativos danos psicossociais (WATHIER; DELL'AGLIO, 2007).

Essas mudanças de comportamento e complicações oriundas do humor depressivo apresentam dificuldades em áreas importantes da fase de desenvolvimento normal da criança. Esses fatores associados a alguns aspectos psicológicos como apatia, tristeza, dificuldade de concentração, isolamento, redução escolar e agressividade, fadiga, solidão, tristeza, perturbação no sono, pessimismo, sentimento de menos valia, de culpa e preocupação são os principais sintomas depressivos observados em uma escola pública (WATHIER; DELL'AGLIO, 2007; FERNANDES; CASTRO, 2011).

Além dessas manifestações sintomatológicas, fatores como facilidade tecnológica em conjunto com falta de regras e limites perante os estímulos externos podem estar gerando crianças e adolescentes depressivos. Nesse sentido, a equipe escolar necessita de estratégias que visem à compreensão dos sinais e sintomas apresentados que fazem parte da sintomatologia depressiva na infância, para que possa fornecer apoio e orientação familiar e, 
consequentemente, sendo necessário o encaminhamento do aluno para um profissional especializado (RIBEIRO et al., 2007).

Como mencionado anteriormente, os sintomas depressivos podem estar associados ao baixo rendimento escolar. Corroborando essa afirmativa, Cruvinel e Boruchovitch (2004) realizaram um estudo que teve como objetivo avaliar a relação entre sintomas depressivos, rendimento escolar e estratégias de aprendizagem em 169 alunos de ambos os sexos, e os resultados apresentados apontaram para a existência de diferenças significativas entre rendimento escolar, sintomas depressivos e repertório de estratégias de aprendizagem dos alunos.

Sobre essas prerrogativas, Cortez (2005) remete que a escola na vida da criança passa a ser o local das primeiras experiências e cobranças sociais e que as respostas aptas a essas exigências estão condicionadas ao seu desenvolvimento físico, psicomotor, cognitivo e afetivo. Ao chegar à escola, a criança sofre um processo de adaptação a partir das mudanças ocorridas, deixando o ambiente protetor familiar e integrando-se aos deveres e às atividades educativas sobre cobranças impostas pelo sistema educacional.

Nesse cenário, a criança precisa cumprir obrigações que são impostas, tais como tarefas e horários, integrar um grupo social, desenvolver habilidades sociais e superar expectativas. Portanto, se a criança tiver algum prejuízo psicológico ou emocional, o contexto escolar poderá tornar-se inacessível e fonte de frustrações (CORTEZ, 2005).

Vale lembrar que sintomas depressivos de ordem psicológica e emocional têm sido recorrentes em resultados de estudos sobre depressão infantil realizados em contextos escolares. Fernandes e Castro (2011), em uma pesquisa com alunos do $1^{\circ}$ ao $4^{\circ}$ anos, de ambos os sexos, do Ensino Fundamental de escola pública e privada, que teve por objetivo averiguar a incidência de sintomas depressivos, concluiu que os principais sintomas depressivos observados foram os de fadiga, solidão, tristeza, perturbação no sono, pessimismo, sentimento de menos valia, de culpa, de preocupação, de desobediência/rebeldia, anedonia e choro.

No entanto, é preciso mencionarque os sintomas depressivos também podem ser encontrados em outros transtornos, o que acaba dificultando um diagnóstico. Thiengo, Cavalcante e Lovisi (2014), em pesquisa de revisão sistemática de literatura que teve como objetivo identificar os transtornos mais prevalentes na infância e na adolescência com possíveis fatores associados, constataram que a depressão estava presente entre os demais transtornos.

Com base nesses dados apresentados, pode-se constatar que atuação do professor no contexto escolar é de extrema relevância para a identificação e a prevenção da depressão em estudantes. $\mathrm{O}$ fato de o professor conviver um tempo maior com o aluno possibilita que ele adquira mais experiências e oportunidades para perceber as alterações no comportamento. Além disso, por não caber ao professor 
a responsabilidade do diagnóstico, este não tem responsabilidade com o resultado final, mas sim com o processo de identificação (CARMO; SILVA, 2009).

Considerando tal problemática, torna-se relevante que o educador disponha de ferramentas que possam auxiliá-lo na identificação precoce de atitudes e comportamentos que desprendem do desenvolvimento normal da criança em sala de aula e que apontam para possíveis sintomas depressivos.

\section{SINTOMAS DEPRESSIVOS EM CONTEXTO ESCOLAR}

A escola tem um papel fundamental na rede de identificação e contenção de sinais e sintomas depressivos, assim como de outros transtornos,podendo ser considerada como o ambiente real para investigar emocionalmente crianças e adolescentes, especialmente por ser um espaço social, relativamente restrito e mediador entre a família e a sociedade, uma vez que é o lugar onde o desempenho dos alunos pode ser avaliado e o professor dispõe de sensibilidade maior para detectar problemas relevantes na vida e no desenvolvimento das crianças (BALLONE; MOURA, 2008).

E, como parte da rede de identificação, no âmbito escolar, o professor geralmente é o primeiro a se deparar com a depressão infantil. A sua experiência e a sua convivência quase que diária com os alunos proporciona um conhecimento básico relacionado a princípios que englobam as alterações no comportamento, no desenvolvimento cognitivo e social das crianças. Como a criança ainda não é capaz de descrever verbalmente seus sentimentos, é necessário observar as formas de comunicação pré-verbal, como a expressão facial, produções gráficas, súbitas mudanças de comportamento, postura corporal, entre outras (BAPTISTA; GOLFETO, 2000). Assim, na maioria das vezes, é o professor que faz o papel de interlocutor entre a criança que apresenta sinais depressivos e a direção/orientação da escola e a família.

Em acréscimo ao que foi postulado, Ballone (2015) afirma que a criança que possui sintomas depressivos apresenta características próprias quanto ao funcionamento psicológico, que diferem do quadro clínico de um adulto na identificação dos sinais e sintomas. Enquanto o adulto deprimido consegue verbalizar suas frustrações, a criança não consegue ter consciência;logo, passa a expor atitudes ou comportamento característico da depressão.

Diante do crescente número de casos de depressão infantil em sala de aula, os professores, sobretudo aqueles das séries iniciais, têm se dedicado à compreensão dos sinais e sintomas desse transtorno, com a finalidade de ter um olhar mais amplo sobre a problemática. Em estudo realizado por Salassi e Peres (2011),cujo objetivo foi investigar o nível de conhecimento de dez pedagogos em relação 
à depressão infantil, os resultados mostraram que,dos dez professores que participaram do estudo, 60\% afirmaram conhecer a depressão infantil e a definiram como transtorno de humor capaz de comprometer e interferir no desenvolvimento mútuo da criança. Dos demais, 30\% declararam que sabiam pouco sobre o assunto, e 10\% confirmaram que somente no ato da pesquisa é que ouviram falar sobre a depressão em crianças.

Em outro estudo, realizado por Carmo e Silva (2009), queteve o intuito investigar o conhecimento que os professores têm a respeito da depressão infantil, concluiu-se que todos os docentes afirmaram conhecer a depressão infantil, por meio de palestras e pesquisa e durante o curso superior. Entretanto, os resultados também mostraram que os professores não conseguem definir com clareza alguns sintomas característicos da depressão.

Nessa conjuntura, é imprescindível a necessidade de destinar mais investimentos para a capacitação do educador que visem ao seu aperfeiçoamento voltado para a saúde mental. Assim, o professor poderá desenvolver e ampliar suas estratégias de identificação e prevenção dos sintomas de transtornos mentais, sobretudo os sintomas depressivos, levando em consideração os aspectos que influenciam nesse processo como: epidemiológicos, sociais, culturais, ecológicos e psicológicos.

Em outras palavras, quanto mais bem preparado estiver o educador para identificar os possíveis sintomas de transtornos mentais no aluno, mais cedo será o encaminhamento para avaliação profissional especializada, como psicólogos e psiquiatras, com o propósito de diagnóstico preciso e formulação de um plano de tratamento.

\section{O QUE O EDUCADOR PODE FAZER?}

O professor em sala de aula, além de ministrar aulas, acompanha a criança durante seu desenvolvimento cognitivo e social, disponibilizando ferramentas capazes de proporcionar à criança experiências novas e educativas, oferecendo a esta novas oportunidades de reconhecimento e crescimento próprios. Entretanto, ao se deparar com uma criança com suspeita de depressão infantil, é necessário que o educador esteja capacitado para lidar com a situação. Espera-se que o docente possa compreender e identificar os principais sintomas desse transtorno, ter o mínimo de entendimento das possíveis causas, para poder ajudar a criança até que esta seja encaminhada a um especialista da área para diagnóstico e, confirmado o transtorno, seja feito o tratamento.

Sendo assim, o educador precisa ficar atento aos sinais apresentados pelo aluno. A criança acometida pelos sintomas depressivos geralmente perde a qualidade dasfunções cognitivas, ocorrendo alterações graves em áreas importantes no cérebro, sofrendo, assim, interferência no desempenho escolar e em outras áreas significativas, 
embora, muitas vezes, sejam imperceptíveis aos olhos dos pais e profissionais da educação (NOGUEIRA; SANTOS; FONSECA, 2016).

Observar as mudanças gradativas no comportamento individual e social do aluno, porque,além de decorrer de fatores genéticos que podem se manifestar de diversas maneiras na vida escolar- trazendo prejuízos ao rendimento e ao convívio social, conforme explicam Nogueira, Santos e Fonseca(2016)-,a depressão afeta as interações com o ambiento e é vista como consequência da diminuição de comportamentos adequados ao contexto social, do interesse pelas atividades e pelas pessoas. Ainda provoca um aumento na frequência de comportamentos de esquiva e fuga de estímulos, vistos como aversivos: tristeza, choro etc. (CRUVINEL; BORUCHOVITCH, 2003).

Vale ressaltar que esses sintomas podem se agravar durante a fase depressiva caso surjam alterações significativas na vida social da criança, tais como morte de ente querido, separação de pais, mudança de escola, perda de amigos, entre outras. Na maioria das vezes, ocorre com queixas habituais, vivenciadas dentro do contexto escolar.

Os principais sinais e sintomas que atuam nas alterações do comportamento da criança se apresentam de maneira diversificada no âmbito escolar. Contudo, Ballone (2015) afirma que os que se apresentam com frequência são: tristeza, ansiedade, cansaço, pessimismo, confiança diminuída de si mesmo, sentimentos de inferioridade, baixa autoestima, ideias de culpa, inutilidade, alteração alimentar e do sono ou, ainda, problemas físicos, tais como dores inespecíficas, fraqueza, tonturas, mal-estar geral, enfim, queixas que não respondem ao tratamento médico habitual.

Associado à manifestação desses sintomas, ainda pode ocorrer o comprometimento emocional, cognitivo e das funções sociais da criança, o que a leva a apresentar sintomas como: dificuldade de concentração, sensação de inutilidade, sensação de culpa exagerada, interesse ou prazer diminuído, ausência de expressão emocional, baixa emotividade e abatimento Fernandes e Milani (2010)e, consequentemente, a dificuldade de aprendizagem do aluno.

A presença de sintomatologia na criança pode interferir diretamente nas atividades associadas à cognição e à emoção. Incorre que, quando essa criança não é tratada a tempo, poderá desenvolver modelos de comportamento como: isolamento, retraimento, dificuldades em se comunicar, entre outros, os quais podem se tornar resistentes a mudanças. (ALLGAIER et al., 2012).

Destaca-se que a demora na procura de tratamento pode ocasionar complicações dos sintomas e prejudicar a recuperação do aluno afetado. Portanto, quando há suspeita ou indícios de sintomas depressivos apresentados pelo 
aluno, cabe ao professor agir de maneira sensível e cautelosa. A identificação feita do início melhora a condição do aluno e o resultado do diagnóstico e prognóstico.

Outro fator a se levar em consideração é que o diagnóstico do transtorno depressivo deve ser investigado e realizado com cautela, pois se assemelha com outros transtornos mentais, exigindo a habilidade e a observação, tanto do psicólogo quanto do professor. Vale lembrar que, nos últimos anos, a depressão infantil tem se apresentado de maneira atípica, com manifestações de comportamento e sentimentos considerados normais pela família e professores. Em muitos casos, a depressão pode se manifestar de forma mais atípica, sendo confundida com outros fatores. Muitas vezes o comportamento alterado da criança em sala de aula, principalmente daquelas mais novas, como medo, irritabilidade, agressividade, hiperatividade, retraimento, rebeldia, pode ser sinal de que ela precisa de ajuda, pois a mudança no comportamento pode ocorrer devido à incapacidade de a criança parar de comunicar verbalmente seu verdadeiro estado emocional (BALLONE, 2015). Ou seja, ela ainda não possui recursos suficientemente comunicativos para externalizar o seu sofrimento e a sua angústia.

Nesse caso, o educador deve ficar atento. E, ao perceber tais alterações, deve comunicar a família e orientá-la a buscar ajuda de um profissional da área da saúde mental para que seja feita a avaliação; se for, necessário o tratamento. Desse modo, além de enfrentar prontamente o problema, anulam-se as falsas interpretações do comportamento do aluno como "frescura" ou "falta de limites" (KUTCHER et al., 2014)). Ballone e Moura (2008) mencionam que existem momentos em que as crianças podem estar tristes, irritadas ou aborrecidas em resposta às circunstâncias diárias; porém, essas manifestações emocionais nãotêm a ver com depressão, pois são fisiológicas e passageiras.

Diante da complexidade do conjunto de fatores envolvente na manifestação de sinais e sintomas depressivos em alunos no contexto escolar, Kutcher et al. (2014) apresentam algumas abordagens que o educador deve utilizar ao se deparar com a manifestação de sintomas depressivos em sala de aula.Além de comunicar a família e, em casos mais graves,encaminhar a profissionais especializados, o professor deve:

Ter uma interação afetiva e não menosprezar o sofrimento do aluno [...]; não deduzir que a criança quieta não está com problemas [...]; buscar compreender a irritabilidade do aluno [...]; enaltecer as qualidades do aluno visando a manter sua autoestima [...]; propor atividades em grupos, para evitar o isolamento do aluno [...]; estar sempre alerto para os sinais de evasão do aluno [...];reforçar o vínculo com os pais [...]; avaliar a necessidade de adaptações das atividades com alunos diagnosticados com depressão [...]; tentar conciliar o currículo com o interesse do aluno, 
quando possível [...]; incentivar as atividades físicas na escola [...]; reforçar positivamente os alunos que demonstrarem comportamentos de apoio em relação ao colega com depressão [...]; encorajar a criança a observar os aspectos positivos das situações e auxiliar a criança a contestar pensamentos negativos. (KUTCHER et al., 2014, p. 140-141).

Vale ressaltar que as abordagens apresentadas anteriormente não se configuram como uma cartilha de enfrentamento à depressão infantil na escola, mas sim dicas que podem facilitar a intervenção do professor no processo de enfrentamento da depressão infantil em sala de aula. Uma vez que cada caso de depressão é único, pois a criança acometida pelos sintomas depressivos, assim como as demais, chega à escola carregada com sua subjetividade constituída a partir das suas relações interpessoais, sua história e sua cultura.

\section{CONSIDERAÇÕES FINAIS}

O presente estudo buscou discutir a importância do educador na identificação e compreensão dos sinais e sintomas depressivos em crianças no contexto escolar. Procurou descrever os principais sintomas da depressão infantil e sua relação com o insucesso escolar do aluno, bem como seu prejuízo nas relações interpessoais neste espaço.

Por meio das fontes consultadas, constatou-se que os transtornos mentais na infância e na adolescência estão crescendo significativamente. E esses transtornos podem estar associados à alteração do desenvolvimento da maioria dos países. No Brasil, os dados têm sido considerados preocupantes em comparação às taxas de crianças de outros países.

Foi possível compreender que as ações de capacitação e informação aos educadores na identificação de sinais e sintomas depressivos, como fenômeno que possui vários fatores determinantes, podem contribuir para um diagnóstico precoce e, consequentemente, para o trabalho de prevenção à saúde infantil.

As informações ressaltadas e discutidas neste trabalho pretenderam mostrar que é preciso levar em consideração as consequências negativas que as síndromes depressivas podem causar na vida da criança, sobretudo no seu desempenho escolar. A manifestação dos sintomas depressivos pode trazer desmotivação para o aprendizado do aluno, comprometer o seu desenvolvimento e influenciar negativamente o seu desempenho escolar e, ainda, trazer prejuízos nas suas relações interpessoais e na sua vida social.

Por se tratar de um assunto recorrente no sistema educacional, a abordagem em saúde mental deve ganhar mais consistência nas escolas e ser integrada com mais frequência como um tema transversal, permeando todo o currículo escolar. É preciso que se desenvolvam e/ou ampliem 
abordagens mais profundas acercados aspectos vinculados à saúde individual e coletiva que buscam sustentação da saúde e do aprendizado no contexto escolar.

Considerando que o professor, por passar mais tempo com o aluno,possui chances maiores no processo de observação de sintomas e sinais de transtornos mentais, faz-se necessária uma capacitação sobre saúde mental para o docente, para que este possa identificar melhor os problemas emocionais e comportamentais e, consequentemente, fazer encaminhamentos mais assertivos ao profissional da saúde especializado. Desse modo, compete à escola aderir a programas e projetos educacionais que envolvam aspectos em nível de conhecimento sobre maneiras de como intervir em sala de aula com alunos que apresentem os respectivos sintomas.

Em suma, entende-se que a função da escola, diante da problemática em questão, deve ser entendida de maneira decisiva e reforçadora no desenvolvimento de ações que viabilizem o trabalho conjunto entre docentes e os demais profissionais da área da educação e da saúde, na criação de estratégias de prevenção e de identificação dos sintomas depressivos no âmbito escolar.

\section{REFERÊNCIAS}

BANDEIRA, Wagner Andriola; CAVALCANTE, Luanna Cavalcante. Avaliação da depressão infantil em alunos da pré-escola. Psicologia: reflexão e crítica, v. 12, n. 2, p. 419-428, 1999. Disponível em: <http://www.redalyc. org/articulo.oa?id=18812211>. Acesso em: 22 set. 2015.

ALLGAIER, A-K;PIETSCH， K.;FRÜHE， B.;PRAST, E.;SIGL-GLÖCKNER, J.; SCHULTE-KÖRNE, G. Depression in pediatriccare: is the WHO-Five Well-Being Index avalid screening instrument for children andadolescents? General Hospital Psychiatry, v. 34, p. 234-241, 2012. Disponível em: <http://www.ncbi.nlm.nih.gov/pubmed/ 22325631>. Acesso em: 20 abr. 2016.

BAPTISTA, C. A.; GOLFETO, J. H. Prevalência de depressão em escolares de 7 a 14 anos. Revista de Psiquiatria Clínica, v. 27, n. 5, p. 253-255, 2000. Disponível em: <http://www.scielo.br/pdf/pcp/v28n3/v28n3a11.pdf>. Acesso em: 15 set. 2015.

BALLONE, G. J. Depressão infantil. 2015. Disponível em: <http://www.psiqweb.med.br/site/?area=NO/ LerNoticia\&idNoticia=339> . Acesso em: 10 maio 2016.

BALlONE, G. J.;MOURA, E. C. Problemas emocionais na escola. 2008. Disponívelem: <http://www. psiqweb.med.br/site/defaultlimpo.aspx? area $=\mathrm{NO} /$ LerNoticia\&idNoticia=127> . Acesso em: 20 abr. 2016. 
BRASIL. Agência Nacional de Saúde Suplementar (ANS). Manual técnico de promoção da saúde e prevenção de riscos e doenças na saúde suplementar. 3. ed. Rio de Janeiro: ANS, 2009.

CARMO, Alessandra Lopes do; SILVA, Ana Paula Barrozo da. Depressão infantil: uma realidade presente na escola. Revista Nucleus, Ribeirão Preto, v. 6, n. 2, p.333-44, out. 2009. Disponível em: <https://dialnet.unirioja.es/servlet/ articulo?Codigo=4034637> . Acesso em: 13 set. 2015 .

CORTEZ, Maira Van Dervis de Mattos. Depressão infantil no contexto escolar: uma análise comportamental. 2005. Disponível em:<http://repositorio.uniceub.br/bitstream/123456789/2858/2/20137355.pdf > . Acesso em: 20 abr. 2016.

CID-10 Classificação Internacional de Doença. 10. ed. São Paulo: Editora da Universidade de São Paulo, 2012.

CRUVINEL, Mirian. Depressão infantil: uma contribuição para a prática educacional. Psicologia escolar e educacional, v. 7, n. 1, p. 77-84, 2003. Disponível em: <http:// www.scielo.br/pdf/pee/v7n1/v7n1ao8.pdf $>$. Acesso em: 20 abr. 2016.

CRUVINEL, Mirian. Regulação emocional em crianças com e sem sintomas de depressão. Estud. psicol., Natal, v. 16, n. 3, p. 219-226, 2011. Disponível em: <http://www.scielo. br/pdf/epsic/v16n3/o3.pdf>. Acesso em: 23 mar. 2016.

CRUVINEL, Mirian; BORUCHOVITCH, Evely. Sintomas depressivos, estratégias de aprendizagem e rendimento escolar em alunos do ensino fundamental. Psicologia em estudo, Maringá, v. 9, n. 3, p. 369-378, 2004. Disponível em: <http://www.scielo.br/scielo.php?pid=S1413$-73722004000300005 \&$ script $=$ sci_abstract\&tlng $=\mathrm{pt}>$. Acesso em: 11 set. 2015 .

CRUVINEL, Mirian; BORUCHOVITCH, Evely. Sintomas depressivos em crianças: estudos com duas versões do CDI. Psicologia: ciência e profissão, v. 28, n. 3, p. 574-585, 2008. Disponível em: <http://www.scielo.br/pdf/pcp/ v28n3/v28n3a11.pdf>. Acesso em: 10 maio 2016.

CRUVINEL, Mirian; BORUCHOVITCH, Evely. Regulação emocional em crianças com e sem sintomas de depressão. Estud. psicol., Natal, v. 16, n. 3, p. 219-226, 2011. Disponível em: <http://www.scielo.br/pdf/epsic/v16n3/o3. pdf>. Acesso em: 23 mar. 2016.

CRUVINEL, Mirian; BORUCHOVITCH, Evely. Compreendendo a Depressão Infantil. Rio de Janeiro: Vozes, 2014 . 
CRUVINEL, Mirian; BORUCHOVITCH, Evely; SANTOS, Acácia Aparecida Angeli dos Santos. Inventário de Depressão Infantil(CDI): Análise dos parâmetros psicométricos. Fractal: Revista de Psicologia. Niterói, v. 25, n. 2, p. 473490, jul./dez. 2008. Disponível em: <http://www.scielo. br/pdf/fractal/v2on2/13.pdf >. Acesso em:9 set. 2015.

DALGALARRONDO, Paulo. Psicopatologia e semiologia dos transtornos mentais.Porto alegre: Artmed, 2008.

DEL PORTO, José Alberto. Conceito de Depressão e seus Limites.In: LAFER, Beny; AMARAL; ALMEIDA, Osvaldo P.; FRAGUAS JR., Renério Fráguas; MIGUEL, Eurípedes C.(Org.). Depressão no Ciclo da Vida. Porto Alegre: Artes Médicas Sul, 2000.p. ?

DSM-V. Manual Diagnóstico e Estatístico de Transtornos Mentais.5. ed. Porto Alegre: Artmed, 2014.

FERNANDES, Giovana Viveiros; CASTRO, Paulo Francisco. Avaliação da incidência de sintomas depressivos em alunos de $1^{\mathrm{a}}$ a $4^{\mathrm{a}}$ série do ensino Fundamental, a partir do inventario de Depressão Infantil (CDI). Revista Saúde-UnG,v. 5, n. 1, p. 21-41, 2011. Disponível em: <http://revistas.ung.br/index.php/saude/article/viewArticle/236>. Acesso em: 20 abr. 2016.

FERNANDES, Andréia Mara; MILANI, Rute Gossi. A depressão infantil, o rendimento escolar e a autoeficácia: uma revisão da literatura. Revista Cesumar-Ciências Humanas e Sociais Aplicadas, v. 15, n. 2, p.381-403, jul./ dez. 2010.

FIHRER, I.; MCMAHON, C. A.; TAYLORT, A. J.The impact of postnatal and concurrent maternal depression on child behavior during the early school years. Journal of Affective Disorders, v. 119, p. 116-123, 2009. Disponívelem: <http://www.ncbi.nlm.nih.gov/pubmed/19342104>. Acesso em: 21 set. 2015.

FONSECA, Fonseca, Maria Helena; FERREIRA, Roberto Asis; FONSECA, Sarah Gonçalves. Prevalência de sintomas depressivos em escolares. Pediatria, v. 27, n. 4, p. 223232, 2005. Disponível em: <https://www.cetcc.com.br/ arquivos/prevalenciadesintomasdepressivosemescolares. pdf $>$. Acesso em: 19 jun. 2016.

GOLFETO, José Hércules; D’OLIVEIRA, Augusto Brandão; BATISTA, Carlos; BISON, Flávia. Prevalência da sintomatologia depressiva nas cidades de Ribeirão Preto e região. Pediatr. mod, v. 47, n. 1, p. 21-24, 2011. Disponível em: <http://www.moreirajr.com.br/revistas.asp fase $=$ roo3\&id_materia $=4545>$. Acesso em: 29 maio 2016. 
HEMERY, J. J.R. Depressão Infantil. Revista do Professor, n. 80. Disponível em: <http://www.projetospedagogicosdinamicos.com/artigo11.htm>. Acesso em:14 ago. 2015 .

HUTTEL, Joseane; KISXINER, Karina Alzira; BONETTI, Rodrigo Alexandre Bonetti; ROSA, Miriam Izolina Padoin Dalla. A depressão infantil e suas formas de manifestação. Psicol. argum, v. 29, n. 64, p. 11-22, 2011. Disponível em: <http://www2.pucpr.br/reol/pb/index.php/ pa?dd1 $=4522 \& d d 99=$ view $\& d d 98=p b>$. Acesso em: 20 abr. 2016.

KONKIEWITZ, E. C. Aprendizagem, comportamento e emoções na infância e adolescência: uma visão transdisciplinar. 2013. Disponível em: <https://scholar. google.com.br/scholar? cluster $=9959887805638185804 \&$ hl=pt-BR\&as_sdt=0,5>. Acesso em: 20 abr. 2016.

KUTCHER, Stan; SOUZA, Érika Leonardo de; PAN, Pedro Mario Pan; COELHO, Roberta Paula Schell; ESTANISLAU, Gustavo. Transtorno de humor-depressão e transtorno bipolar. In: ESTANISLAU, Gustavo M.; BRESSAN, Rodrigo A. Saúde mental na escola: o que os educadores devem saber. Porto Alegre: Artmed, 2014. p. 133-152.

LAFER, Beny; AMARAL, José Antônio de Mello Siqueira. Depressão no ciclo da vida. Porto Alegre: Artmed, 2000.

LIMA, Dênio. Depressão e doença bipolar na infância e adolescência. Jornal de Pediatria, v. 80, n. 2, p. 11-20. 2004. Disponível em: <http://www.scielo.br/pdf/jped/ v8on2so/v8on2Sa03.pdf>. Acesso em: 11 out. 2015.

MILLER, Jeffrey A. O livro de referência para depressão infantil. São Paulo: M. Books do Brasil Editora Ltda, 2003.

NOGUEIRA, Tayrine de Barros; SANTOS, Geovana Maria dos; FONSECA, Grazzieni Clemente. Implicações da depressão no rendimento escolar da criança. 2016. Disponível em: <http://www.unipacto.com.br/revista2/arquivos_dia_09-04/implica\%C3\%A7oes.pdf >. Acesso em: 20 abr. 2016.

RIBEIRO, Karla Carolina Silveira; OLIVEIRA, Josevânia da Silva Cruz de, COUTINHO, Maria da Penha de Lima; ARAÚJO, Ludgleydson Fernandes de. Representações sociais da depressão no contexto escolar. Paidéia, Ribeirão Preto, v. 17, n. 38, p. 417-430, 2007. Disponível em: $<$ http://www.scielo.br/pdf/paideia/v17n38/v17n38a11. pdf>. Acesso em: 20 abr. 2016.

ROCHA, Tiago Humberto Rodrigues; RIBEIRO, João Eduardo Caixeta; PEREIRA, Gilberto de Araújo; AVEIRO, 
Cristiana Chaves; SILVA, Liliane Cristina de Além-Mar e. Sintomas depressivos em adolescentes de um colégio particular. Psico USF, v. 11, n. 1, p. 95-102, jan./jun. 2006. Disponível em: <http://pepsic.bvsalud.org/pdf/psicousf/ v11n1/v11n1a11.pdf $>$. Acesso em: 21 jun. 2016.

SALASSI, Edilainde Regina; PERES, Tatiane dos Passos. Comprometimento da aprendizagem por sintomas depressivos em crianças no âmbito escolar. Revista OMNIA Humanas, v. 3 , n. 1, p. 44-53, 2011. Disponível em: <http://www.fai.com.br/portal/ojs/index.php/omniahumanas/article/view/83>. Acesso em: 21 jul. 2016.

SOUZA, Thaís Rabanea de; LACERDA, Acioly Luiz Tavares de. Depressão ao longo da história. In: QUEVEDO, J. SILVA, A. G. (Org.).Depressão: teoria e clínica. Porto Alegre: Artmed, 2013.p. 17-28.

THIENGO, Daianna Lima; CAVALCANTE, Maria Tavares; LOVISI, Giovanni Marcos. Prevalência de transtornos mentais entre crianças e adolescentes e fatores associados: uma revisão sistemática. J. bras. psiquiatr, v. 63, n. 4, p. 360-372, 2014. Disponível em: <http://www.scielo.br/ pdf/jbpsiq/v63n4/o047-2085-jbpsiq-63-4-0360.pdf $>$. Acesso em: 14 abr. 2016.

VINOCUR, Evelyn; PEREIRA, Heloisa Viscaíno F. S. Avaliação dos transtornos de comportamento na infância. Revista Hospital Universitário Pedro Ernesto, v. 10, n. 2, p. 26-34, 2011. Disponível em: <http://revista.hupe.uerj.br/ detalhe_artigo.asp?id=103>. Acesso em: 20 abr. 2016.

WATHIER, Josiane Lieberknecht; DELL'AGLIO, Débora Dalbosco. Sintomas depressivos e eventos estressores em crianças e adolescentes no contexto de institucionalização. Revista de Psiquiatria do Rio Grande do Sul, v. 29, n. 3, p. 305-314, 2007.Disponível em: <http://www.scielo.br/pdf/rprs/v29n3/v29n3a10.pdf>. Acesso em: 20 abr. 2016.

Recebido em: $31 / 10 / 2016$ Aprovado em: 21/04/2017 